\title{
URINARY 2,5-HEXANEDIONE IN WORKERS EXPOSED TO N-HEXANE: INFLUENCE OF THE SAMPLE TREATMENT
}

Daniela Magalhães Nolasco, Andréia Gusmão and Maria Elisa Pereira Bastos de Siqueira*

Departamento de Análises Clínicas e Toxicológicas, Universidade Federal de Alfenas, Rua Gabriel Monteiro da Silva, 714, 37130-000 Alfenas - MG, Brasil

Recebido em 24/2/06; aceito em 6/9/06; publicado na web em 26/3/07

\begin{abstract}
The aim of the present study was to determine 2,5-hexanedione (2,5-HD), a metabolite of n-hexane, by gas chromatography/flame ionization detection in 31 workers exposed to n-hexane after two types of sample pretreatment, i.e., with (total 2,5-HD) and without (free 2,5-HD) acid hydrolysis. The mean urinary 2,5-HD was $0.52 \mathrm{mg} / \mathrm{L}$ (free) and $2.88 \mathrm{mg} / \mathrm{L}$ (total), this difference being significant (Student $\mathrm{t}$-test, $\mathrm{p} \leq 0.05$ ). The differences in the results according to the sample treatment support the need to modify the current Brazilian legislation, which proposes the analysis of $2,5-\mathrm{HD}$ without indicating whether it is the free or total metabolite.
\end{abstract}

Keywords: 2,5-hexanedione; biomonitoring; sample pretreatment.

\section{INTRODUCTION}

$\mathrm{n}$-Hexane (HEX) is an important constituent of petroleum and is used as an organic solvent in polishing products, paints and glues, in the extraction of vegetable oil, in polyethylene and polypropylene lamination, as a diluent in the production of plastics and rubbers, in tire production, and in the pharmaceutical and cosmetic industry, as well as in the composition of gasoline, in dry cleaners' products, in tissue manufacturing, and in printers' shops ${ }^{1}$.

Hexane started to be used worldwide on a large scale mainly after the prohibition of the use of benzene as solvent. In Brazil, this prohibition was established by Decree No. 3 (1982), with HEX being one of the indicated replacements due to its solvent properties that are closely similar to those of benzene at equivalent costs $^{2}$.

According to the Fundacentro/SP which analyzed 83 different glue brands in Brazil, HEX is the main solvent present in these glues $^{2}$. Workers are mainly exposed through inhalation, but direct skin contact with the glue is also observed. Among the nociceptive effects of HEX, peripheral neuropathy is the most severe and has been recognized as an occupational disease ${ }^{3,4}$. Neuropathy is caused by the main HEX metabolite, 2,5-hexanedione (2,5-HD), which binds to DNA, RNA and axon proteins ${ }^{5-7}$.

The most widely used bioindicator in the monitoring of workers exposed to HEX is urinary 2,5-HD due to its high correlation with environmental exposure to HEX as reported by various investigators ${ }^{8-10}$.

Biological monitoring of HEX was done by the determination of total urinary 2,5-HD after acid hydrolysis, with the recommended limits being $5 \mathrm{mg}$ 2,5-HD/g creatinine for exposure to the Threshold Limit Value-Time Weight Average (TLV-TWA) of $50 \mathrm{ppm}$ HEX in air $^{11}$. In the Brazilian legislation the same limit is adopted, but it does not mention the use or not of previous hydrolysis for the determination of urinary 2,5-HD ${ }^{12}$. In 2003, the American Conference of Governmental Industrial Hygienists (ACGIH) ${ }^{13}$ recommended the determination of free 2,5-HD, with a biological exposure index of $4.0 \mathrm{mg} / \mathrm{L}(3.5 \mu \mathrm{M} / \mathrm{L})$. The decision was based on the fact that other HEX metabolites (4,5-dihydroxy-2-hexanone and 5-hydroxy-2-hexanone) are converted into 2,5-HD during

*e-mail: marelisa@unifal-mg.edu.br hydrolysis ${ }^{14,15}$. The validity of the use of total $2,5-\mathrm{HD}$, in contrast to the free metabolite, for the biomonitoring of exposure to HEX has been a matter of controversy.

Gas chromatography/mass spectrometry (GC/MS) or gas chromatography/flame ionization detection (GC/FID) is the technique most widely used for the quantification of 2,5-HD in urine ${ }^{15-18}$, in addition to high-performance liquid chromatography using a reverse-phase column and UV or fluorescence detection ${ }^{19,20}$.

Regardless of the analytical method used, the urine samples need to be pretreated prior to chromatographic analysis. The objective of the present study was to determine 2,5-HD in workers of a shoe factory in Brazil and to analyze the results after two types of sample pretreatment, i.e., with or without acid hydrolysis.

\section{EXPERIMENTAL}

\section{Chemicals}

2,5 - hexanedione was purchased from Sigma-Aldrich Inc., Saint Louis, USA, and 5-methylhexanone-2 (internal standard) from Merck, Darmstadt, Germany. Stock solutions $(1.0 \mathrm{mg} / \mathrm{L}$ of 2,5-HD and $0.5 \mathrm{mg} / \mathrm{L}$ of the IS) were prepared in methanol and stored at $-20{ }^{\circ} \mathrm{C}$ for at maximum 3 months. Dilute solutions were prepared just before use in purified water (MilliQ). Organic solvents and other chemicals and reagents were of analytical grade.

\section{Apparatus}

The gas-chromatography system CG1000 DPC from CGS ${ }^{\circledR}$ (São Paulo, Brazil) was equipped with a flame ionization detector. The signals were integrated using a DANI ${ }^{\circledR}$ integrator (Milan, Italy). 2,5-HD was separated on a $100 \%$ polydimethylsiloxane $\mathrm{HP}^{\oplus}$ capillary column $(30 \mathrm{~m} \times 0.53 \mathrm{~mm}, 0.5 \mu \mathrm{m}$ thick film) using the following oven temperatures: initial temperature of $60{ }^{\circ} \mathrm{C}$ for 2 min, followed by increases of $10{ }^{\circ} \mathrm{C} / \mathrm{min}$ up to $127{ }^{\circ} \mathrm{C}$ maintained for $5 \mathrm{~min}$, and subsequent increments of $40{ }^{\circ} \mathrm{C} / \mathrm{min}$ up to $200{ }^{\circ} \mathrm{C}$ maintained for $3 \mathrm{~min}$. The temperatures of the injector and detector were 200 and $250{ }^{\circ} \mathrm{C}$, respectively. Nitrogen was used as the mobile phase at a flow rate of $8 \mathrm{~mL} / \mathrm{min}$, and $1 \mu \mathrm{L}$ of the sample was injected in the splitless mode. 


\section{Extraction procedure}

One-hundred microliters of the 5-methylhexanone-2 solution $0.5 \mathrm{mg} / \mathrm{L}$ (internal standard), $2 \mathrm{~g} \mathrm{Na}_{2} \mathrm{SO}_{4}$ and $1 \mathrm{~mL}$ chloroform were added to $10 \mathrm{~mL}$ urine. After vortex-mixed for $2 \mathrm{~min}$, the sample was centrifuged at 2,300 x $g$ for $15 \mathrm{~min}$. One microliter of the organic extract was injected onto the column. Another $10 \mathrm{~mL}$ aliquot of the same urine sample was supplemented with $600 \mu \mathrm{L} \mathrm{37 \%}$ hydrochloric acid, $\mathrm{pH}<0.5$. The sample was heated to $100{ }^{\circ} \mathrm{C}$ for 30 min for acid hydrolysis, and then extracted with chloroform.

\section{Validation parameters}

For the definition of the validation parameters, urine pools obtained from volunteers, who declared to be nonsmokers and not exposed to HEX or any other organic solvent during the last 2 weeks, were spiked with 2,5-HD standards. Before fortifying the urine pools with $2,5-\mathrm{HD}$, these samples were analyzed to certify the absence of detectable levels of the metabolite. Linearity was determined by the addition of the 2,5-HD standard solution to urine samples to obtain concentrations of 0.1 to $30.0 \mathrm{mg} / \mathrm{L}$. These samples were analyzed in six replicates per concentration. The limit of detection (LOD) for 2,5-HD was estimated as a signal-to-noise ratio of 3, whereas the limit of quantification (LOQ) was defined as the lowest amount of analyte in urine that provided a response with a precision of less than $10 \%$ and with an accuracy between 80 and $120 \%$. Precision and relative recovery were determined using quality control (QC) samples prepared at four concentrations $(0.1,1.0,5.0$ and $10 \mathrm{mg} / \mathrm{L})$. Each of the QC samples were replicated $(n=6)$. The precision was calculated as the coefficient of variation $(\mathrm{CV})$ within a single run (intra-day). Relative recovery was determined submitting the spiked samples to liquid-liquid extraction, and comparing the peak areas obtained with those resulting from the direct addition of the standards to the blank urine extract.

\section{Population and urine collection}

Thirty-one volunteers ( 8 men and 23 women), ranging in age from 19 to 42 years, working at a shoe factory in the city of Franca, São Paulo, Brazil, who handled HEX-containing glues were studied. Six of the volunteers reported moderate consumption of alcoholic beverages (7-20 g/week) and four were smokers (5-12 cigarettes/ day). Their work consisted of removing and applying glue with a leather brush without the use of any individual protection equipment. The work week comprised $8 \mathrm{~h} /$ day, $40 \mathrm{~h} /$ week. The spot samples were collected after the $5^{\text {th }}$ day of the week's work, as recommended by $\mathrm{ACGIH}^{13}$, and transported under refrigeration to the laboratory where they were stored at $-20{ }^{\circ} \mathrm{C}$ until analysis, performed 2-3 days after collection. The volunteers provided data regarding their personal and work habits using a toxicological protocol. The study was approved by the Research Ethics Committee of the Institution and the subjects signed an informed consent form to participate. The concentration of 2,5-HD was reported as $\mathrm{mg} / \mathrm{L}$, without correction, and as $\mathrm{mg} / \mathrm{g}$ creatinine after correction for urinary creatinine.

\section{RESULTS AND DISCUSSION}

The method used for the analysis of 2,5-HD in urine was based on the proposal of Perbellini et al. ${ }^{21}$, with modifications. The sample and reagent volumes were altered and chloroform was used, which showed a better recovery than dichloromethane proposed by the authors cited. The analytical curve was linear between 0.1 and 30.0 $\mathrm{mg}$ 2,5-HD/L of urine and the following equation was obtained: $y$ $=0.1189 \mathrm{x}-0.0188$, y representing the ratio of $2,5-\mathrm{HD}$ area to internal standard area, showing significant linearity $\left(\mathrm{R}^{2}=0.998\right)$.

The LOD and LOQ of the method were 0.05 and $0.10 \mathrm{mg} / \mathrm{L}$, respectively. These values are similar to those reported by Perbellini et al. ${ }^{21}$ and lower than the $0.14 \mathrm{mg} / \mathrm{L}$ LOQ reported by van Engelen et $a l .{ }^{22}$ and the $0.97 \mathrm{mg} / \mathrm{L}$ LOD reported by Hamelin et al. ${ }^{16}$, both obtained after liquid-liquid extraction.

Table 1 shows the coefficients of variation and \% recovery obtained for the concentrations studied in samples submitted to acid hydrolysis and without this pre-treatment. The values for the two validation parameters were similar to those reported by other investigators ${ }^{18,22}$. Intra-assay variation was slightly higher when the samples were previously hydrolyzed, probably due to the addition of reagents and additional operations compared to direct extraction.

Table 1. Within-series precision and recovery of the 2,5-hexanedione chromatographic method (with and without hydrolysis)

\begin{tabular}{lcrcr}
\hline \multirow{2}{*}{$\begin{array}{l}2,5-\mathrm{HD} \text { in } \\
\text { urine }(\mathrm{mg} / \mathrm{mL})\end{array}$} & \multicolumn{2}{c}{$\begin{array}{c}\text { Coefficient } \\
\text { of variation (\%) }\end{array}$} & \multicolumn{2}{c}{$\begin{array}{c}\text { Recovery } \\
(\%)\end{array}$} \\
& without & with & without & with \\
\hline 0.1 & 8.9 & 10.0 & 94.6 & 96.2 \\
1.0 & 2.4 & 5.2 & 95.8 & 99.2 \\
5.0 & 1.4 & 2.5 & 99.1 & 98.9 \\
10.0 & 1.0 & 3.8 & 99.0 & 97.0 \\
\hline
\end{tabular}

Based on the characteristics established, the method was found to be adequate for application to various situations of occupational exposure to HEX.

Statistical parameters relating to urinary concentrations of free and total 2,5-HD in urine of exposed workers, expressed as $\mathrm{mg} / \mathrm{l}$ and $\mathrm{mg} / \mathrm{g}$ creatinine, are shown in Table 2 .

Table 2. Free and total 2,5-HD (in $\mathrm{mg} / \mathrm{L}$ and $\mathrm{mg} /$ creatinine) from workers exposed to glue solvents

\begin{tabular}{|c|c|c|c|c|}
\hline \multirow[t]{2}{*}{$\begin{array}{l}\text { Parameters } \\
\mathrm{n}=31\end{array}$} & \multicolumn{2}{|c|}{$\begin{array}{c}2,5-\mathrm{HD} \\
(\mathrm{mg} / \mathrm{L})\end{array}$} & \multicolumn{2}{|c|}{$\begin{array}{c}2,5-\mathrm{HD} \\
(\mathrm{mg} / \mathrm{g} \text { creatinine })\end{array}$} \\
\hline & free & total & free & total \\
\hline Mean* & 0.52 & 2.88 & 0.49 & 2.47 \\
\hline SD & 0.31 & 1.20 & 0.43 & 1.50 \\
\hline Minimum & 0.29 & 1.70 & 0.12 & 0.91 \\
\hline Maximum & 1.86 & 7.38 & 2.05 & 7.63 \\
\hline Median* & 0.42 & 2.44 & 0.34 & 2.06 \\
\hline Geometric mean & 0.47 & 2.70 & 0.38 & 2.18 \\
\hline R 95\% percentile & 0.99 & 4.72 & 1.44 & 5.64 \\
\hline BEI (ACGIH 2003) & 0.40 & 5.00 & & \\
\hline
\end{tabular}

* significant difference between treatments, $P<0.01$

In all workers the levels of total 2,5 $\mathrm{HD}$ were higher than the free metabolite, with interindividual variations in the free/total ratio (Figure 1).

The free/total 2,5-HD ratio ranged from 0.10 to 0.30 (mean of $0.19)$. These interindividual variations in the free/total ratios might be explained by co-exposure to other solvents in the glue used by shoemakers (the main ones including ketones, toluene, xylenes) which can interfere with the biotransformation of HEX because they use the same P-450 oxidizing enzimatic system. On the other hand, the conversion of other HEX metabolites to 2,5-HD after acid hydrolysis, in variable amount, also affect the urinary 


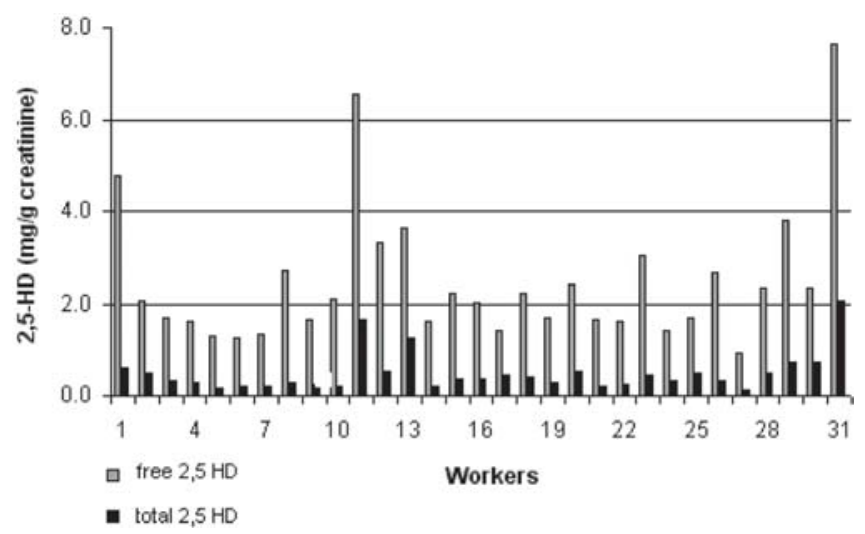

Figure 1. Concentrations of 2,5-HD found in the samples of workers exposed to glue solvents in shoe industries (without and with acid hydrolysis). The limit value adopted in Brazil is $5 \mathrm{mg} / \mathrm{g}$ creatinine, not specifying if it is for the total or free metabolite

concentration of the 2,5 $\mathrm{HD}^{23-25}$. Manini et al. ${ }^{15}$ observed wide variations in 2,5-HD concentration in hydrolyzed samples as a result of incomplete conversion of other HEX metabolites to 2,5-HD.

In view of interindividual differences in the biotransformation of any chemical compound, it is expected that the increase in 2,5HD after hydrolysis will also vary among workers. Thus, the 2,5HD concentrations detected in samples not submitted to hydrolysis are more specific for the toxic metabolite and, in the absence of homogeneity in the free/total ratio among different individuals, application of these results might lead to errors in the interpretation of data regarding a given environmental exposure to HEX. Hamelin et al. ${ }^{16}$ did not detect 2,5-HD in volunteers not exposed occupationally to HEX or in samples not submitted to hydrolysis, in contrast to hydrolyzed samples, a fact also indicating that the free compound better differentiates human beings exposed to the solvent from non-exposed ones.

Free 2,5-HD has been evaluated in a limited number of studies and almost always in environments characterized by simultaneous exposure to other solvents ${ }^{12,23,25,26}$. Hamelin et al. ${ }^{27}$ determined free urinary 2,5-HD excretion and HEX in alveolar air in five volunteers exposed to HEX (25-50 ppm) for 5 consecutive days and concluded that both free urinary 2,5-HD and HEX in alveolar air are adequate indicators in the biomonitoring of exposure to HEX.

Figure 2 shows the correlation between free and total 2,5-HD levels expressed in $\mathrm{mg} / \mathrm{g}$ creatinine $(\mathrm{r}=0.9127)$ and in $\mathrm{mg} / \mathrm{L}(\mathrm{r}=$ 0.7578 ). The better correlation between free and total 2,5-HD for results corrected according to the creatinine levels was probably due to collection of samples after a single urine excretion (spot sample).

The fact that the workers did not use masks during work certainly contributed to an increased introduction of solvents through inhalation, especially in a country with a hot climate most of the time of the year like Brazil. Percutaneous absorption, considered to be a significant route of introduction of HEX, may also have contributed since the workers did not use gloves during application of the product.

It is also important to analyze the results in view of the limits established for urinary 2,5-HD. In Brazil, this limit is $5 \mathrm{mg} / \mathrm{g}$ creatinine, with no reference to the use or not of previous hydrolysis which, as shown, yields highly different results. If we consider this value, which was also recommended by the DFG in 2002 for total urinary $2,5-\mathrm{HD}^{28}$, only $2(6.5 \%)$ of the workers were excessively exposed to HEX. If we consider only free $2,5-\mathrm{HD}$ and its limit proposed by the ACGIH in 2003, i.e., $0.4 \mathrm{mg} / \mathrm{L}$, this number rises to 19 workers $(61.3 \%)$. These data demonstrate the importance of a well-defined mode of expression of the results that will better protect the health of workers.
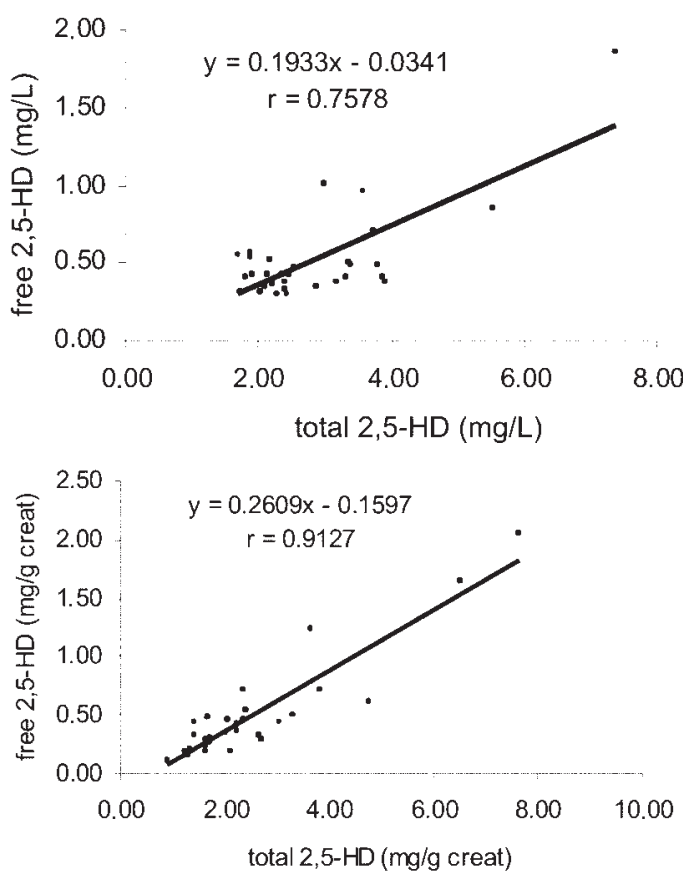

Figure 2. Correlation of free and total urinary 2,5-hexanedione, expressed in $\mathrm{mg} / \mathrm{L}$ and in $\mathrm{mg} / \mathrm{g}$ creatinine

\section{CONCLUSIONS}

From the point of view of interpretation of the results of biological monitoring, the measurement of free 2,5-HD is more valuable than the total 2,5-HD because it better evaluates the true exposure of workers to HEX. Then, using no urine hydrolysis prior to SPE extraction is recommended. The large differences observed between free and total metabolite support the need for modifying the current Brazilian legislation, which proposes the analysis of 2,5-HD, expressed as $\mathrm{mg} / \mathrm{g}$ creatinine, without indicating whether it is the free or total metabolite. In addition, correction of the results for urinary creatinine as recommended for various bioindicators also seems to be preferable for 2,5-HD, with the corrected results showing a better free/total correlation than uncorrected data.

\section{ACKNOWLEDGMENTS}

The authors wish to thank J. A. Leite for his technical assistance. Financial support from the CNPq (Conselho Nacional de Desenvolvimento Científico e Tecnológico) and FNDCT/CT/INFRA/Efoa, convênio 0990/01.

\section{REFERENCES}

1. World Health Organization (WHO); Environmental Health Criteria 22- nHexane, WHO: Geneva, 1991.

2. Silva, M. R. S.; Bombardi, S. M. J.; Olle, R. D; Fagá, I.; Possebon, J.; Buschinelli, J. T. P.; Atual. Prev. Acid. 1991, 22, 6.

3. Pastore, C.; Izura, V.; Marhuenda, D.; Prieto, M. J.; Roel, J.; Cardona, A.; Muscle Nerve 2002, 26, 132.

4. Sanagi, S.; Seki, Y.; Sugimoto, K.; Hirta, M.; Int. Arch. Occup. Environ. Health 1980, 47, 69.

5. Graham, D. G.; Curr. Opin. Neurol. 1999, 12, 733.

6. Governa, M.; Calisti, R.; Coppa, G.; Tagliavento, G.; J. Toxicol. Environ. Health 1987, 20, 128

7. LoPachin, R. M.; He, D.; Reid, M. L.; Neurotoxicology 2005, 26, 229.

8. Cardona, A.; Marhuendad, D.; Prieto, M. J.; Marti, J.; Periago, J. F.; Sanchez, J. M.; Int. Arch. Occup. Environ. Health 1996, 68, 88.

9. Mayan, O.; Teixeira, J. P.; Pires, A. F.; Appl. Occup. Environ. Hyg. 2001, $16,763$. 
10. Prieto, M. J.; Marhuenda, D.; Roel, J.; Cardona, A.; Toxicol. Lett. 2003 $145,249$.

11. American Conference of Governmental Industrial Hygienists (ACGIH); Threshold Limit Values and Biological Exposure Indices, ACGIH: Cincinnati, 1986.

12. Brasil, Secretaria de Segurança e Saúde no Trabalho, Portaria 24, de 29 de dezembro de 1994; Diário Oficial, Brasília, 1994, p. 21278-21282.

13. American Conference of Governmental Industrial Hygienists (ACGIH); Threshold Limit Values and Biological Exposure Indices for 2003, ACGIH: Cincinnati, 2003.

14. Fedtke, N.; Bolt, H. M.; Int. Arch. Occup. Environ. Health 1986, 57, 149.

15. Manini, P.; Andreoli, R.; Mutti, A.; Bergamaschi, E.; Franchini I.; Toxicol. Lett. 1999, 108, 225.

16. Hamelin, G.; Truchon, G.; Tardif, R.; Int. Arch. Occup. Environ. Health 2004, 77, 264.

17. Perbellini, L.; Leone, R.; Fracasso, M. E.; Brugnone, F.; Venturini, M.S.; Int. Arch. Occup. Environ. Health 1982, 50, 351

18. Santos, C. R.; Passarelli, M. M.; Nascimento, E. S.; J. Chromatogr., B: Anal. Technol. Biomed. Life Sci. 2002, 778, 237.

19. Andreoli, R.; Manini, P.; Mutti, A.; Bergamaschi, E.; Niessen, W. N.; Rapid Commun. Mass Spectrom. 1998, 12, 1410.
20. Maestri, L.; Ghitori, S.; Imbriani, M.; Capodaglio, E.; J. Chromatogr., B: Anal. Technol. Biomed. Life Sci. 1994, 657, 111.

21. Perbellini, L.; Brugnone, F.; Faggionato, G.; Br. J. Ind. Med. 1981, 38, 20.

22. van Engelen, J. G. M.; Kesic, S.; Haan, W.; Opdan, J. J. G.; Woll, F. A.; J. Chromatogr., B: Anal. Technol. Biomed. Life Sci. 1995, 667, 233.

23. Cardona, A.; Marhuendad, D.; Marti, J.; Brugnone, F.; Roel, J.; Perbellini, L.; Int. Arch. Occup. Environ. Health 1993, 65, 71.

24. Kawai, T.; Myama, Y.; Horiguschi, S.; Sakamoto, K.; Zhang,Z. W. Higashikawa, K.; Ikeda, M.; Int. Arch. Occup. Environ. Health 2000, 73, 449.

25. Kawai, T.; Yasugi, T.; Mizunuma, K.; Horiguschi, S.; Uchida, Y.; Iwai, O.; Iguchi, H.; Ikeda, M.; Int. Arch. Occup. Environ. Health 1991, 63, 285.

26. Kawai, T.; Myama, Y.; Mizunuma, K.; Horiguschi, S.; Iguchi, H.; Uchida, Y.; Iwai, O.; Ikeda, M.; Int. Arch. Occup. Environ. Health 1992, 64, 223.

27. Hamelin, G.; Charest-Tardif, G.; Truchon, G.; J. Occup Environm. Hyg. 2005, 2, 86.

28. Deutsche Forschungsgeinschaft (DFG); List of MAK and BAT Values 2002, Maximum Concentration and Biological Tolerance Values at the Workplace, Wiley: Weinheim, 2002. 